\title{
Les actes de langage dans les organisations de Gino Gramaccia, L'Harmattan Paris, 2001, 287 pages
}

Hugues Hotier

\section{OpenEdition}

1 Journals

Édition électronique

URL : http://journals.openedition.org/communicationorganisation/2540

DOI : 10.4000/communicationorganisation.2540

ISSN : $1775-3546$

Éditeur

Presses universitaires de Bordeaux

Édition imprimée

Date de publication : 1 mai 2001

ISSN : 1168-5549

\section{Référence électronique}

Hugues Hotier, «Les actes de langage dans les organisations de Gino Gramaccia, L'Harmattan Paris, 2001, 287 pages », Communication et organisation [En ligne], 19 | 2001, mis en ligne le 27 mars 2012, consulté le 20 avril 2019. URL : http://journals.openedition.org/communicationorganisation/2540 ; DOI : 10.4000/communicationorganisation.2540

Ce document a été généré automatiquement le 20 avril 2019

(c) Presses universitaires de Bordeaux 


\title{
Les actes de langage dans les organisations de Gino Gramaccia, L'Harmattan Paris, 2001, 287 pages
}

\author{
Hugues Hotier
}

1 Autant le dire tout de suite, j'aime beaucoup Gino Gramaccia. J'aime l'homme, j'aime le chercheur, j'aime l'auteur. Il est de ceux qui mine de rien, vous forcent à la réflexion parce qu'ils posent les problèmes différemment, parce qu'ils créent des rapprochements inattendus, parce qu'ils perturbent les certitudes. Mine de rien. Professeur à l'Université Bordeaux I, Gino Gramaccia est aussi un remarquable pédagogue et cela transparaît dans ses écrits pour le plus grand bonheur du lecteur.

2 «L'idée exprimée par l'Anglais John L. Austin que « dire, c'est faire » doit être poussée jusqu'à ses ultimes conséquences.». Cette phrase tirée de la Théorie générale de l'information et de la communication de Robert Escarpit, est placée en exergue de l'ouvrage. Elle ne saurait être mieux choisie car c'est bien des ultimes conséquences de la théorie des actes de-langage que traite Gino Gramaccia. Celle-ci trouve une illustration parfaite dans les organisations contemporaines. Les nouvelles formes de travail (projets, ingénierie concourante, équipes de plateaux) démontrent de manière éclatante la priorité accordée au lien communicationnel, lui-même créé par l'acte de langage. Lorsque l'auteur écrit : «Loin de partager l'optimisme méthodologique et éthique de Zarifian, qui perçoit dans ces formes l'émergence d'une communication intersubjective qui constituerait, pour les acteurs impliqués dans des situations professionnelles transdisciplinaires (des techniciens, des vendeurs, des estimateurs...), l'opportunité enfin inventée de l'expression du vrai, de l'authentique, de la subjectivité, je fais l'hypothèse que ces formes d'organisation instituent au contraire les conditions subtiles d'une autonomie paradoxale. Le paradoxe veut qu'il n'y ait d'autres critères du succès productif qu'économiques (la qualité, les cô̂ts, les délais). Quant à l'autonomie, elle découle simplement d'une règle pratique de délégation de décision, par l'autorité classique, aux détenteurs des savoirs stratégiques investis pour la résolution de problèmes complexes" il fait à la bonne connaissance du terrain qu'il possède. Car c'est là une deuxième caractéristique de Gino Gramaccia: les structures ad hoc des projets technologiques qu'il a pu observer, voire 
pratiquer, lui fournissent un matériau de choix pour éprouver la théorie d'Austin et l'examiner dans les circonstances les plus diverses.

3 Constamment sous-jacente. la question de la posture épistémologique du chercheur n'est pas escamotée. Le chercheur en sciences de l'information et de la communication est-il voué à l'impasse par la nature même de la discipline? Gino Gramaccia répond par la négative en exposant brillamment les logiques communicationnelles susceptibles de donner à cette discipline nouvelle l'homogénéité au moins partielle qu'elle recherche et dont elle a besoin. Ici encore, et d'une manière particulièrement heureuse, l'auteur s'appuie à la fois sur son vécu de chercheur et sur les théories les plus fiables. L'analyse stratégique de Crozier et Friedberg bien sûr mais aussi la dynamique du changement organisationnel et les processus conversationnels de James R. Taylor. Cette fructueuse approche $\mathrm{du}$ chercheur canadien, connue depuis quelques années seulement, est parfaitement assimilée et exposée par Gino Gramaccia qui la résume adroitement par la formule "L'organisation advient dans et par la communication ».

4 La multiplicité des références et leur intelligente mise en perspective donnent à cet ouvrage une force remarquable en ancrant les apports personnels d'une indéniable valeur théorique dans la pratique professionnelle soigneusement observée et remarquablement analysée. En bref. Gino Gramaccia apporte ici, de manière brillante, la preuve de son aptitude à conceptualiser à partir d'une connaissance exceptionnelle du milieu industriel et de ses méthodes managériales tout autant que des théories de l'organisation, de la communication et de la communication des organisations qu'il analyse remarquablement. Son approche critique, fine et intelligente, des auteurs et des textes témoigne à la fois d'un grand savoir et d'une capacité à dominer les sujets les plus complexes sans jamais se départir d'une modestie qui l'honore.

5 Cet ouvrage a une autre qualité que je tiens à souligner: il est écrit dans une langue soignée et claire avec un sens de la formule et une justesse de la métaphore qui ne peuvent manquer de séduire le lecteur. 